\title{
Manuel Rivero Rodríguez. El conde duque de Olivares. La búsqueda de la privanza perfecta, Madrid, Polifemo, 2017, 326 págs.
}

Considerando la importancia del personaje del Conde-Duque de Olivares (1587-1645), valido de la primera parte del reinado de Felipe IV, llama la atención el escaso número de biografías, sean clásicas o recientes, que existen sobre él. Esto contrasta, por ejemplo, con el caso del Duque de Lerma, valido de Felipe III, quien ha sido biografiado numerosas veces en las últimas décadas. Parecía durante mucho tiempo que la monumental obra de Sir John H. Elliott sobre el conde-duque (1986, 1990 en español) iba a ser la última palabra acerca del tema.

Pasarían unas tres décadas hasta que Manuel Rivero dedicara otra obra completa a este personaje clave de la historia de España y de Europa de la primera mitad del siglo XVII. Sobre el autor no hace falta decir muchas cosas. Se trata de uno de los más reconocidos expertos de la monarquía hispánica de los Austrias, lo cual ha quedado en evidencia con múltiples publicaciones, tanto libros como artículos científicos, en las últimas más de dos décadas.

Rivero nos presenta un planteamiento distinto a la actuación política de Olivares, en sus propias palabras, "alejado de la "pasión de mandar" con que lo caracterizó Marañón y aún más lejos del "hombre de estado en una época de crisis" retratado por Sir John H. Elliott". En suma, se aleja de conceptos y tópicos consolidados por la tradición que parte de Cánovas, pasa por Marañón y termina en Elliott. El libro se trata, además, de una biografía del valido Olivares y no de la persona Gaspar de Guzmán y Pimentel Ribera y Velasco de Tovar, ya que se centra casi exclusivamente en los años en la cabeza del gobierno de Felipe IV.

Para ello, el autor pone en entredicho al documento clave que has la fecha ha servido para explicar e interpretar la actuación política de Olivares, el famoso Gran Memorial de 1624. Como ya lo había hecho en un artículo previo, Rivero cuestiona la autoría del conde-duque de dicho documento en el primer capítulo que a su sirve como un repaso historiográfico, llegando a la conclusión de que hasta ahora no se ha sido capaz de explicar la política de Olivares sin este memorial.

Los cinco capítulos que siguen abordan los sucesivos periodos del valimiento, combinando las políticas interior y exterior. El capítulo 2 caracteriza el estilo del valimiento de Olivares, dejando sobre todo dos cosas: primero, que no se hace con el poder en el momento que accede al trono Felipe IV en 1621. Es en un primer momento su tío, Baltasar de Zúñiga, quien ejerce principalmente el poder, estando Olivares más bien en segunda línea como parte de su equipo de gobierno. Solo con la muerte de Zúñiga en octubre 1622, Olivares se hace poco a poco con el poder, quedando finalmente consolidado en el viaje a Andalucía del rey en 1624. Segundo, el tiempo inicial dominado por Zúñiga no se puede considerar un simple preludio del valimiento de Olivares, ya que tío y sobrino tenían diferencias conceptuales muy importantes 
en cuando al propio valimiento y al gobierno. En cuanto al primer punto, Zúñiga tenía una visión negativa del valimiento, considerándolo causa de la corrupción y decadencia de la monarquía. Olivares, en cambio, creía que el problema no era el valimiento en sí sino las personas corruptas que lo corrompían. En cuanto al gobierno, si bien Olivares la idea de su tío de que la monarquía necesitaba regenerarse, sus medios serían bien distintos. Zúñiga quería recuperar los consejos, devaluados en el reinado anterior, como institución clave del gobierno. Olivares, en cambio, gobernaba de forma más informal y mediante juntas más bien espontáneas.

Otro énfasis que hace Rivero es la importancia del catolicismo para la identidad y la política de la monarquía, importancia que volvió fuertemente con Olivares. Esto queda en evidencia en el tercer capítulo donde sirve como explicación de por qué Olivares no concluye el proyecto de alianza matrimonial con Inglaterra, que había sido promovido por Zúñiga. El autor explica el fracaso de esta alianza con la potencia protestante, que habría sido beneficiosa desde un punto de vista geopolítico, por los escrúpulos de conciencia del conde-duque que no creía que dicho matrimonio fuera a contribuir a la restauración del catolicismo en Inglaterra.

El capítulo 4 está dedicado principalmente al gobierno de la monarquía y de sus distintos territorios. Aparte del ya mencionado desmantelamiento de los consejos y la importancia de las juntas, Rivero destaca la figura de los virreyes. Para el autor, se estaría volviendo a un sistema de virreyes puros de la época de Carlos V. Se destaca en que gobernaban los distintos reinos de forma casi autónoma, no haciendo caso muchas veces a las instrucciones de la corte, lo cual a su vez llevaba a menudo a quejas y protestas desde los reinos. Con lo anterior Rivero demuestra justamente que el problema denunciado por los súbditos y vasallos no era una monarquía centralizada (o el proyecto de aquello) sino todo lo contrario, una monarquía, por decirlo de alguna forma, excesivamente descentralizada, en la cual el rey y la corte apenas intervenían en el gobierno de los distintos territorios.

Al mismo tiempo, Rivero evidencia el intento de incorporar a los naturales de los distintos reinos en el gobierno de sus territorios, lo cual no sería contradictorio a estos virreinatos absolutos sino nuevamente todo lo contrario, ya que los naturales se vincularían a las cortes virreinales en vez de mantener agentes en Madrid, con lo cual los asuntos de cada territorio se mantendrían dentro del mismo.

Los capítulos 5 y 6 explican el apogeo en el poder y el declive cuyo inicio se ubica durante la década de los 1630. También en la explicación del fracaso de la política de Olivares Rivero se distancia de la interpretación tradicional de que las reformas expuestas en el Gran Memorial y su puesta en práctica lo habrían causado, ya que, como ya se ha mencionado, dicho proyecto para el autor nunca existió. Para Rivero, la causa se halla principalmente en que le surge oposición y resistencia desde dos sectores que Olivares creía sus aliados, la Iglesia, por una parte, y la nobleza, por otra. 
La guerra abierta con Francia, la otra gran potencia católica, en 1635 dejó en evidencia que la confesionalidad ya no era la ideología que dirigía la guerra. Ello ponía en entredicho la legitimación del proyecto político de Olivares que era la lucha contra la corrupción moral y de las costumbres. En cuanto a la nobleza, si bien es cierto que Olivares despreciaba a la gente de condición no noble y no confiaba en ellos, Rivero explica que la mayoría de dicho estamento terminó por estar en desacuerdo con la política del conde-duque hacia ellos. Las exigencias, primero de contribuir a la guerra y después, desde la década de 1630, la restitución a la corona de rentas, jurisdicciones y tasas indebidamente apropiadas por los nobles, hacía crecer una fuerte oposición al conde-duque dentro de su propio estamento. Rivero concluye que al proyecto de Olivares le faltaba precisamente el respaldo moral, otorgada por la religión y que sin éste perdía toda legitimidad.

En conclusión, Manuel Rivero nos presenta otro conde-duque, muy distinto al que conocíamos y creíamos saber cómo era. No es el Olivares que quería crear una monarquía centralizada a la castellana, gobernada desde la corte, sino uno que entregaba el poder a los virreyes para que gobernaran con plenos poderes desde los propios territorios. La otra clave para entender al conde-duque es el catolicismo, primero como eje de su proyecto de combatir la corrupción moral y después para entender el fracaso de su política al abandonar la confesionalidad.

El libro constituye un enfoque novedoso que necesitaba la investigación del conde-duque, el cual además resta sobre una más que sólida base documental y bibliográfica. Se podrá estar de acuerdo o no con este planteamiento o parte de él y sin duda, habrá mucha discusión acerca de ello, pero serán discusiones necesarias que solo gracias a este libro se hacen posibles, ya que dejó claro en cualquier caso que el personaje no estaba resuelto como parecía asumido.

Matthias Gloël Universidad Católica de Temuco-CHILE 